\title{
Successful Discrimination Using Otolith Microchemistry Among Samples of Red Snapper Lutjanus campechanus from Artificial Reefs and Samples of L.campechanus Taken from Nearby Oil and Gas Platforms
}

\author{
Lauren Nowling ${ }^{1}$, R.W. Gauldie ${ }^{3}$, J. H. Cowan, Jr. ${ }^{1 *}$ and E. De Carlo ${ }^{2}$ \\ ${ }^{I}$ Department of Oceanography and Coastal Sciences, Louisiana State University, Baton Rouge, LA 70803-7503, USA; \\ ${ }^{2}$ SOEST, University of Hawai'i At Manoa, Honolulu Hi 96822, USA; ${ }^{3}$ Merit Nz Limited, 76 Inglis Street, Wellington \\ 6022, New Zealand.
}

\begin{abstract}
A total of 98 Lutjanus campechanus otoliths were analyzed by ICPMS from collections made from both artificial reefs and oil and gas platforms in Alabama and Louisiana over a two-year period from 2002 to 2003. The 15 stable isotopes analyzed in this study were ${ }^{51} \mathrm{~V},{ }^{59} \mathrm{Co},{ }^{62} \mathrm{Ni},{ }^{64} \mathrm{Zn},{ }^{66} \mathrm{Zn},{ }^{65} \mathrm{Cu},{ }^{107} \mathrm{Ag},{ }^{109} \mathrm{Ag},{ }^{110} \mathrm{Cd},{ }^{111} \mathrm{Cd},{ }^{114} \mathrm{Cd},{ }^{206} \mathrm{~Pb},{ }^{207} \mathrm{~Pb},{ }^{208} \mathrm{~Pb}$ and ${ }^{238} \mathrm{U}$. This suite of elements was chosen because they were most likely to be present at oil and gas platforms in the metals and other materials used in artificial reefs, and in the circulating heavy "muds" used while drilling wells. A series of statistical analyses were performed to establish the statistical structure of the data. Linear and stepwise discriminant analyses were performed to show that by using subsets of all the elements measured, it was possible to discriminate among artificial reefs and oil and gas platforms at average misclassification rates of the order of $10 \%$.
\end{abstract}

Keywords: Lutjanus campechanus, otolith, chemistry, oil and gas platforms, artificial reefs.

\section{INTRODUCTION}

The total catch of Red Snapper (Lutjanus campechanus Poey) in the Northern Gulf of Mexico has paralleled the development of oil and gas platforms off the US Gulf coastline, and more latterly the extensive development of artificial reefs in the same, or closely adjacent, areas. A natural question is to ask to what extent do oil and gas platforms and artificial reefs contribute to the standing stocks of $L$. campechanus as nursery grounds, or act as adult feeding grounds? There is a substantial literature dealing with the commonly observed association with oil and gas platforms and artificial reefs of $L$. campechanus, as well as many other species of fish and invertebrates [1-4]. Many studies have confirmed that some L. campechanus do indeed spend some periods of their lives in association with oil and gas platforms and with artificial reefs. But the key question of just how long, and at what stages in its life, does L. campechanus spend time at or near oil and gas platforms and artificial reefs remains largely unanswered. The key to answering this most basic question is to find some marker in an individual fish that would allow fisheries managers to refer part, or whole, of a fish's life either to oil and gas platforms or to artificial reefs.

This study was carried out to assess the suitability of at least some aspects of the microchemistry of the otolith of Lutjanus campechanus as a useable tool to differentiate among individual fish caught at oil and gas platforms and

*Address correspondence to this author at the Department of Oceanography and Coastal Sciences, Louisiana State University, Baton Rouge, LA 70803, USA; Tel: 225-578-9400; E-mail: jhcowan@1su.edu fish caught at artificial reefs. Otolith chemistry has had a long-held promise of being a useable tool for understanding exactly this aspect of fish population dynamics. Some uses of the chemistry of the otolith are already well-established reliable tools used by fisheries managers. These tools include marking hatchery juveniles [5] and detecting life history boundaries in the chemical record of the otolith of fishes that cross steep environmental gradients in temperature, chemistry, or other stress-related factors $[6,7]$. But in the area of stock dynamics that is of interest to fisheries managers (basically some variation on stock separation), otolith chemistry has not proved to be as useable as its success in other areas might suggest. In part, this is due to the definition of what is a "stock". Fisheries managers have historically followed either the American West Coast fishery notion of stocks, or the Atlantic fishery notion of stocks [8]. The West Coast fishery stock [9] focuses on homogeneity in management characters of a group of fish, e.g. growth rate, fecundity etc. The Atlantic fishery stock [10] focuses on an isolated, selfsustaining population, regardless of any inherent homogeneity in management characters. Neither the Marr [9] type of stock nor the Gulland [10] type of stock is related to otolith chemistry. At present, a widely accepted definition of a stock in fisheries science is from Begg et al. [11]: “... a "stock"... describes characteristics of semi-discrete groups of fish with some definable attributes that are of interest to fisheries managers". The definition of Begg et al. [11] is closer to Marr [9] than to Gulland [10] and carries the implication that local ecological conditions, particularly the food supply that controls growth rate, are integrated into the notion of stocks.

From the earliest papers exploring otolith chemistry as a population marker $[12,13]$, to more recent publications [14], 
it is evident that the otolith chemistry signal is so strongly influenced by individual variation that the long-sought population marker has proved to be often more apparent than real. A key source of the individual variation that contributes to the noise in otolith chemistry is likely to be the variation in $\mathrm{pH}$ in the endolymphatic fluid. The effects of varying $\mathrm{pH}$ on aragonite chemistry are well known [15]. In addition, some elements such as zinc are regulated physiologically in fish body fluids and tissues [16] so that the levels of zinc and other physiological elements in the otolith may not be correlated to environmental levels. One possible way to avoid the individual variation in the chemical concentrations of elements in the otolith that can be expected from $\mathrm{pH}$ fluctuations, or physiological effects, would be to use a chemical marker that is more likely to be associated with a known chemical source that gives the substrate, or the water column at a particular location, or an estuarine inflow, a distinctive chemical signature. This approach also falls into line with the stock definition of Begg et al. [11]. We thought that this approach might be possible in those parts of the Northern Gulf of Mexico where oil and gas platforms and artificial reefs are sited. This is because, firstly, the water is relatively shallow facilitating bottom / water-column mixing; secondly, because the Mississippi River plume that represents the powerful and well-mixed signal of isotopes emanating from the industrialized and agrarian mid-west flows west to east across the shallow water of the Northern Gulf; and, thirdly, the materials out of which oil and gas platforms and artificial reefs have been constructed are well known so that their probable chemical signature can be expected to be unlike the natural background chemistry. In effect, the artificial reefs and the oil and gas platforms of the coastal Gulf of Mexico off Louisiana and Alabama constitute an enormous, manmade "experiment of nature". This situation provides us with potential opportunities to not only better understand the causes of variation in the microchemistry of otoliths, but also to understand the relationship between local ecological conditions and otolith chemistry.

Lead isotopes in the microchemistry of otoliths were used by Spencer et al. [17] on the basis of the difference in isotope signatures between petrol lead additives that contaminate the sediment and near-sediment water column in Kaneohe Bay, and the ambient near-shore lead isotopes that have naturally dissolved from the basaltic base rock of the island of Oahu, Hawai'i. The success of the lead isotope study in Hawai'i lead us to carry out a similar approach to the problem of site identification central to the management of $L$. campechanus. This paper addresses the basic question of whether a suite of isotopes of heavy metals measured from the otoliths of L. campechanus can distinguish among fishes that have resided at artificial reefs and fishes that have resided at oil and gas platforms?

\section{MATERIALS AND METHODS}

\section{Lutjanus campechanus Collection}

The specimens of Lutjanus campechanus analyzed $(\mathrm{N}=$ 98) for this study ranged in size from $318 \mathrm{~mm}$ to $776 \mathrm{~mm}$ in total length. By location, 32 otoliths came from Louisiana oil and gas platforms (site 1) in the South Timbalier Circle off the Louisiana coast which is located in Bureau of Ocean En- ergy Management, Regulation and Enforcement lease blocks $128,134,135,151$ and 152; 31 otoliths came from Louisiana artificial reefs (site 2) south of Port Fourchon, Louisiana; and 35 otoliths came from Alabama artificial reefs (site 3) 15 to 20 miles south of Dauphin Island in a grid of artificial reefs located within the Hugh Swingle Permit Area. Exact catch locations cannot be given in order to maintain confidentiality with the boat captains and skippers who provided us with our specimens. Map 1 shows the sampling area.

Fish were measured for total length $(\mathrm{mm} \pm 1)$ and sex was noted. The head of each fish was removed using an electrical fillet knife. The heads were placed in individual plastic storage bags and then stored on ice until they were returned to Louisiana State University (LSU) for otolith removal. For otolith processing at a later date, heads were kept frozen to minimize contamination.

\section{Otolith Removal and Preparation}

For all otoliths analyzed, the heads were thawed in the laboratory in sealed plastic bags inside collection containers. Dissection and handling tools were cleaned first with 18megohm water, followed by rinsing with quartz-distilled water (QED). Laboratory surfaces were cleaned with deionized water (DI) and covered with clean paper. All samples were dissected in a clean (Class-100) laboratory.

The original otolith digestion procedure used by Spencer et al. [17] using heat lamps to dry down samples was modified to a procedure using microwave digestion. The new procedure allowed for 11 samples and one blank to be digested at a time and the digestion took less time than the previous method. Otoliths were prepared using the microwave digestion procedure; otherwise, preparation followed Spencer et al. [17].

\section{Microchemistry Measurements}

The 15 stable isotopes analyzed in this study were ${ }^{51} \mathrm{~V}$, ${ }^{59} \mathrm{Co},{ }^{62} \mathrm{Ni},{ }^{64} \mathrm{Zn},{ }^{66} \mathrm{Zn},{ }^{65} \mathrm{Cu},{ }^{107} \mathrm{Ag},{ }^{109} \mathrm{Ag},{ }^{110} \mathrm{Cd},{ }^{111} \mathrm{Cd},{ }^{114} \mathrm{Cd}$, ${ }^{206} \mathrm{~Pb},{ }^{207} \mathrm{~Pb},{ }^{208} \mathrm{~Pb}$ and ${ }^{238} \mathrm{U}$. These elements are not the usual suite of elements used in otolith microchemistry measurements. This suite of elements were chosen because they were most likely to be present at oil and gas platforms, in the metals and other materials used in artificial reefs, and in the circulating heavy "muds" used while drilling wells [18-20]. These heavy elements are also known to replace calcium in the aragonite matrix [21]. In the text the term "stable isotopes of heavy elements" is reduced to "elements" or "elemental composition" except where confusion may arise.

Otoliths of $L$. campechanus were processed in a Fisons/VG PlasmaQuad® inductively coupled plasma-mass spectrometer using flow injection analysis (FIA) for the presence of 15 different elements or isotopes. The flow injection system pulses a sample through the ICP-MS in a continuous flow of cleaning solution to reduce the amount of sample required and lessen the build up of deposits on the sampler and skimmer cones. The ICP-MS standard used for comparison of elemental recovery was comprised of L. campechanus otolith material gathered in the Gulf of Mexico and analyzed at the National Standards Laboratory [James H. Cowan, Jr. - personal communication]. Apart from the $L$. 


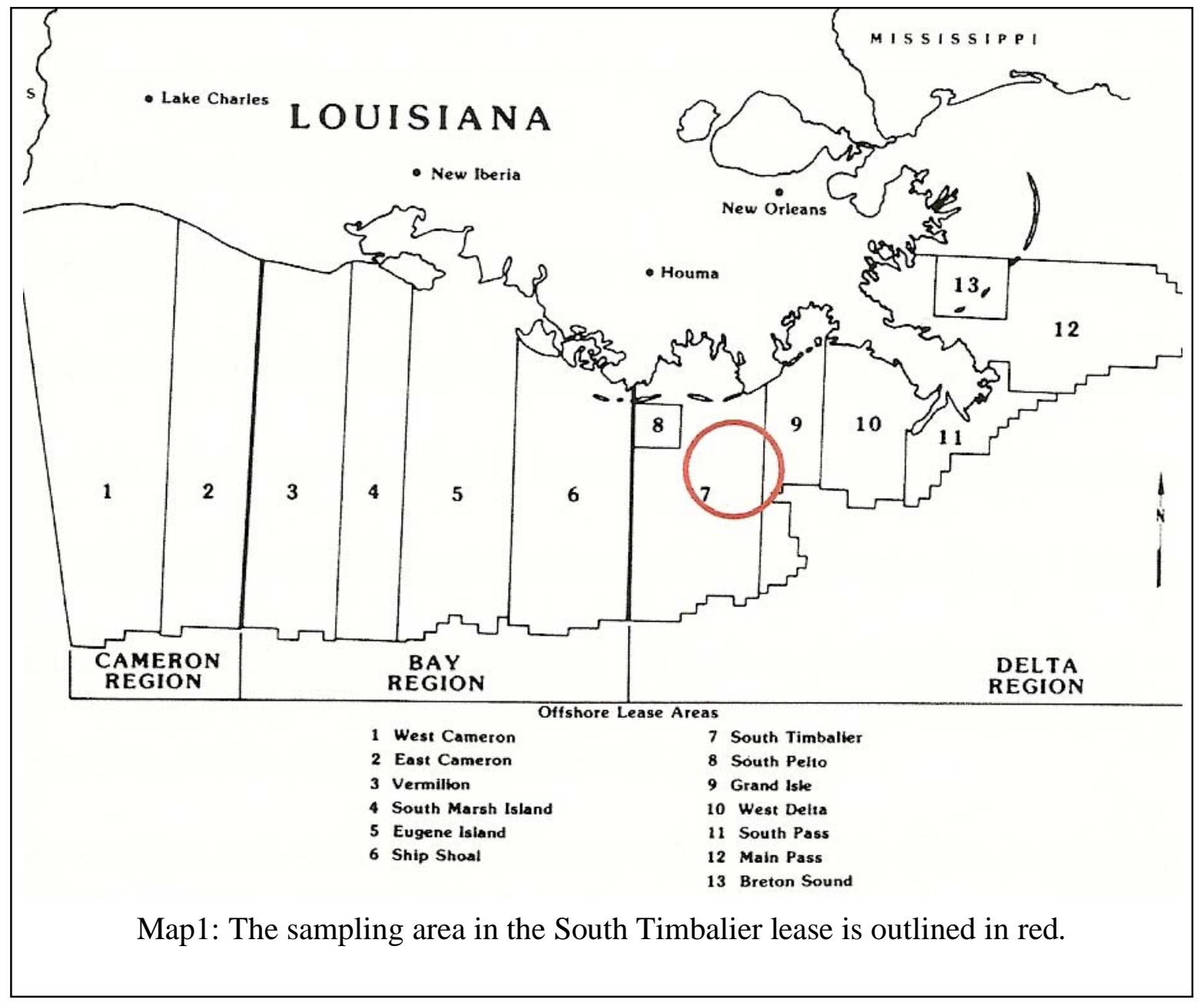

campechanus otolith standard material, the methods and standardization of blanks followed Spencer et al. [17]. The details of the otolith microchemistry measurements are available in Nowling [22].

\section{Statistical Treatment of Data}

All data obtained from mass spectrometry was standardized to a concentration measure $[X]_{\text {sample }}$ using the following equation:

$$
[X]_{\text {sample }}=\frac{\left(\left[X_{\text {solution }}-X_{\text {blank }}\right][\text { solution weight }][\text { dilution factor }]\right)}{\text { sample weight }}
$$

The differences in otolith chemistry between sample sites were so great that the distinction between sample sites can be seen by eye. In such circumstances, our tiered statistical analyses are aimed as much at understanding the variation in the data as they are aimed at confirming the apparent discontinuity in otolith chemistry between the sample sites. Different statistical methods were applied stepwise to define not only the variation in the elemental composition of otoliths from each environment tested (platforms and artificial reefs), but also the degree of overlap between artificial reefs from Louisiana and artificial reefs form Alabama, and between oil and gas platforms and artificial reefs within Louisiana (Table
1). The methods are as follows in the order in which they were applied:

1. Differences between environments for individual elements or isotopes were tested using Multivariate Analysis of Variance (MANOVA) to determine which isotopes were most important in inter-environment fingerprint differences. A probability level of 0.05 was used to define statistical significance.

2. A principal components analysis (PCA) was used to describe the variation in the ICP-MS data gathered for all the study sites combined. This analysis is used to describe the variation in a set of multivariate data in terms of a set of new, uncorrelated variables, each of which is a particular linear combination of the original variables [23]. The main objective of this analysis was to determine whether the first few principal components accounted for a large part of the variation in the data, in which case they can be used to provide a suitable summary of the complete data set. The correlation matrix was used in this analysis as opposed to the covariance matrix because the ${ }^{64} \mathrm{Zn}$ and ${ }^{66} \mathrm{Zn}$ concentrations were higher than the concentrations of the other 13 isotopes analyzed.

3. Unique signatures of each environment were determined using discriminant function analysis, with all isotopes as dependent variables. Using a set of observations contain- 
ing one or more quantitative dependent variables and a classification variable defining groups of observations, discriminant function analysis computes linear or quadratic discriminant functions classifying observations of $L$. campechanus otolith chemistry into two or more groups (platforms vs. reefs) on the basis of one or more of the quantitative variables (elements and isotopes). The discriminant functions (classification criterion) that are derived will be stored so that they can be used as the basis of comparison for any future studies using otolith chemistry of L. campechanus.

A stepwise discriminant analysis (SDA) was used to determine what elements were the most influential in discriminating between oil and gas platforms and artificial reefs in the Gulf of Mexico. Stepwise discriminant analysis finds a set of the original quantitative variables that best discriminate among the two sites or groups. A significance value of 0.05 was used in the analysis to determine when variables were chosen to enter and leave the discriminant function. To exclude variables that are highly correlated, the singular statement was set at a value of 0.2 . Singularity is equal to 1 minus the tolerance, so setting the singularity to 0.2 infers an optimum tolerance value of 0.8 . Tolerance values range from 0 to 1 and a small value indicates a high correlation between that variable with one or more of the other variables included in the discriminant function.

4. A canonical discriminant analysis (CDA) was also used to compare the otolith chemistry of L. campechanus from artificial reef and oil and gas platforms. The canonical discriminant procedure determines the best linear combinations of the quantitative variables in which the means of the groups are most different. The canonical discriminant analysis was performed three times, first to compare the elemental concentration of otoliths from all sites, second to compare otoliths from both Louisiana sites, and third to compare otoliths from the two artificial reefs sites (Louisiana and Alabama) east and west of the Mississippi River. All statistical analyses were performed using SAS Version 9.0.

We report in outline the preliminary statistical analyses leading up to the CDA, which is described in detail. The full details of all the statistical analyses are reported in the thesis of Nowling that can be downloaded from the Louisiana State University library website [22].

\section{RESULTS}

\section{Multivariate Analysis of Variance (MANOVA)}

A MANOVA was used to compare the means of all 15 elements in otoliths between each of the study sites. Ten of the 15 elements analyzed had statistically significantly different means in otoliths collected from Louisiana oil and gas platforms (site1), Louisiana artificial reefs (site 2), and Alabama artificial reefs (site 3). These 10 elements, and their corresponding $\mathrm{p}$-values, were as follows: ${ }^{59} \mathrm{Co}(\mathrm{p}=0.0070)$, ${ }^{64} \mathrm{Zn}(\mathrm{p}=0.0339),{ }^{65} \mathrm{Cu}(\mathrm{p}=0.0255),{ }^{107} \mathrm{Ag}(\mathrm{p}<0.0001)$, ${ }^{109} \mathrm{Ag}(\mathrm{p}<0.0001),{ }^{110} \mathrm{Cd}(\mathrm{p}=0.0091),{ }^{111} \mathrm{Cd}(\mathrm{p}=0.0229)$, ${ }^{114} \mathrm{Cd}(\mathrm{p}=0.0012),{ }^{206} \mathrm{~Pb}(\mathrm{p}=0.0464)$, and ${ }^{207} \mathrm{~Pb}(\mathrm{p}=$ $0.0331)$. The elements ${ }^{208} \mathrm{~Pb}(\mathrm{p}=0.0958)$ and ${ }^{238} \mathrm{U}(\mathrm{p}=$ 0.0888 ) were close to being significantly different between the three sites, with p-values greater than 0.05 but less than 0.10 . The MANOVA results showed that 8 of the 15 ele- ments in question had significantly different means in otoliths from Louisiana oil and gas platforms and Louisiana artificial reefs. The elements were ${ }^{51} \mathrm{~V}(\mathrm{p}=0.0001),{ }^{64} \mathrm{Zn}(\mathrm{p}$ $=0.0035),{ }^{66} \mathrm{Zn}(\mathrm{p}=0.0003),{ }^{107} \mathrm{Ag}(\mathrm{p}=0.0015),{ }^{109} \mathrm{Ag}(\mathrm{p}=$ $0.0001),{ }^{206} \mathrm{~Pb}(\mathrm{p}=0.0075),{ }^{207} \mathrm{~Pb}(\mathrm{p}=0.0092)$, and ${ }^{208} \mathrm{~Pb}(\mathrm{p}$ $=0.0094)$.

The MANOVA showed that mean values of 9 of the 15 elements analyzed were significantly different when otoliths from the two artificial reef sites were compared, i.e. one site in Louisiana and one site in Alabama (sites 2 and 3). These differences may be caused by water mass chemical characteristics east and west of the Mississippi River that are affected by the westward flowing Mississippi plume. The elements that have significantly different means are ${ }^{51} \mathrm{~V}(\mathrm{p}=$ $0.0048),{ }^{65} \mathrm{Cu}(\mathrm{p}<0.0001),{ }^{66} \mathrm{Zn}(\mathrm{p}=0.0495),{ }^{107} \mathrm{Ag}(\mathrm{p}=$ $0.0001),{ }^{109} \mathrm{Ag}(\mathrm{p}=0.0107),{ }^{114} \mathrm{Cd}(\mathrm{p}=0.0004),{ }^{206} \mathrm{~Pb}(\mathrm{p}=$ $0.0218),{ }^{208} \mathrm{~Pb}(\mathrm{p}=0.0103)$, and ${ }^{238} \mathrm{U}(\mathrm{p}=0.0374)$. The means of ${ }^{59} \mathrm{Co}(\mathrm{p}=0.0588),{ }^{110} \mathrm{Cd}(\mathrm{p}=0.0720)$, and ${ }^{207} \mathrm{~Pb}(\mathrm{p}$ $=0.0529$ ) are close to being statistically significantly different, with p-values larger than 0.05 but less than 0.10 .

The MANOVA results showed that there was sufficient structure in the covariance between samples to warrant principal component analysis.

\section{Principal Components Analysis}

Principal components analysis (PCA) was performed using all 98 observations to determine the variation in the data set. The 15 elements analyzed in this study were included in the analysis as variables. Based on the results of the PCA, and when referring to the eigenvalues of the correlation matrix, the first four principal component scores explained $70 \%$ of the variance in the ICP-MS data. The first two principal component scores alone explained $47 \%$ of the variance suggesting that these two scores, for each of the elements analyzed, provided an adequate description of the data. When referring to the eigenvectors of principal components 1 and 2, a number of different elements accounted for the variation in the ICP-MS data. The elements ${ }^{107} \mathrm{Ag},{ }^{109} \mathrm{Ag},{ }^{110} \mathrm{Cd},{ }^{111} \mathrm{Cd}$, ${ }^{114} \mathrm{Cd},{ }^{206} \mathrm{~Pb},{ }^{207} \mathrm{~Pb}$, and ${ }^{208} \mathrm{~Pb}$ have some of the largest eigenvectors and appeared to explain the greatest portion of the variance at principal component 1 . When referring to principal component $2,{ }^{64} \mathrm{Zn},{ }^{66} \mathrm{Zn},{ }^{51} \mathrm{~V},{ }^{59} \mathrm{Co}$ ' and ${ }^{62} \mathrm{Ni}$ had the largest eigenvectors.

PCA confirmed that there was a sufficient degree of discrimination among the data from all three sites to warrant deeper statistical analysis.

\section{Linear and Stepwise Discriminant Analysis}

\section{(i) Comparison between All Study Sites}

Linear discriminant analysis (LDA) was performed using all 98 observations to determine if study sites could be discriminated based upon the elemental composition of otoliths. The variables used include the 15 elements analyzed, and the classes consisted of the 3 sites previously designated. The F approximations for all of the multivariate statistics in this analysis were significant with $\mathrm{p}$-values $<0.0001$, indicating that it is possible to discriminate between the 3 sites based upon L. campechanus otolith elemental composition. It was also apparent that the two artificial reef sites (site 2 and site 


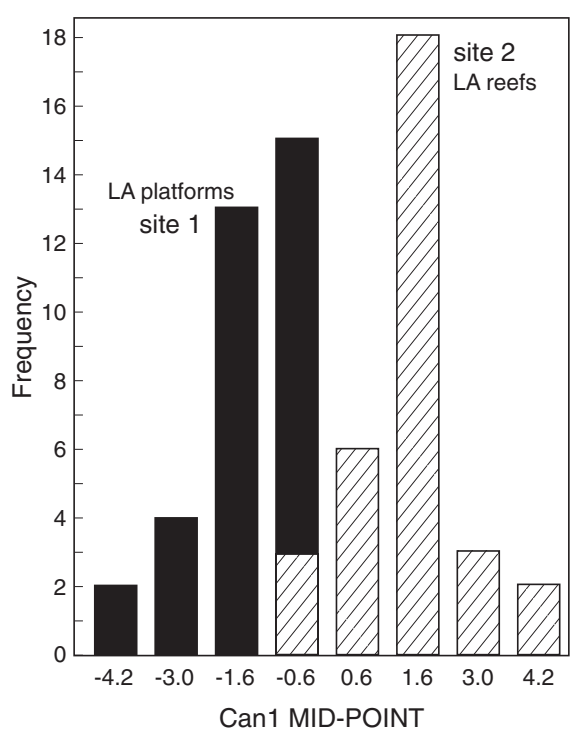

Fig. (1). Vertical bar-graph of canonical variable 1, with observations separated by site, for a comparison of the chemistry of otoliths of Lutjanus campechanus collected from Louisiana oil and gas platforms (site 1) and Louisiana artificial reefs (site 2).

3) could not be combined as one large sample because of the differences in the elemental composition of otoliths collected in these areas. Overall, the LDA resulted in a crossvalidation misclassification rate of $19.51 \%$.

A stepwise discriminant analysis (SDA) was then used to determine which elements were most important in discriminating otoliths from fish collected among the sites. All 98 observations were included in the analysis (PROC STEPDISC; SAS V 9.0), the 15 elements analyzed in the study were used as variables, and the 3 sites remained as class levels. Results of the SDA indicated that 9 of the 15 elements are useful to discriminate among otoliths collected from the 3 sites. These 9 elements were ${ }^{107} \mathrm{Ag}{ }^{66} \mathrm{Zn},{ }^{51} \mathrm{~V},{ }^{208} \mathrm{~Pb},{ }^{114} \mathrm{Cd}$, ${ }^{59} \mathrm{Co},{ }^{65} \mathrm{Cu},{ }^{238} \mathrm{U}$ and ${ }^{62} \mathrm{Ni}$. The LDA was then rerun comparing otoliths from all 3 sites, but using only the 9 elements identified above; the number of observations and the classes remained the same. Rerunning the LDA using these 9 elements lower the cross-validation misclassification rate from $19.51 \%$ to $15.03 \%$.

The chemistries of otoliths collected from all of the study sites were statistically significantly different in elemental composition. Thus, the gas platform data cannot be combined with the artificial reef data. Therefore, two other discriminant analyses were performed. The first analysis compared otolith chemistries between L. campechanus otoliths from Louisiana oil and gas platforms (site 1) and Louisiana artificial reefs (site 2). The second analysis compared otolith chemistries between Louisiana and Alabama artificial reef samples (sites 2 and 3) i.e. L. campechanus otoliths collected from east and west of the Mississippi River.

\section{(ii) Comparison between Louisiana Sites}

The elemental compositions of L. campechanus otoliths from Louisiana oil and gas platforms (site 1) and Louisiana artificial reefs (site 2) were compared using LDA to determine if otoliths from the two sites could be successfully discriminated. The analysis included a total of 63 L. campecha- nus otoliths (32 from site 1 and 31 from site 2), 15 variables or elements, and 2 classes (site 1 and site 2). All four of the multivariate statistics and their exact $F$ statistics were significant, with $\mathrm{p}$-values $<0.0001$. Otoliths from site 1 and 2 could be successfully discriminated using this procedure, and the analysis resulted in a cross-validation misclassification rate of $15.83 \%$. An SDA was then performed to determine the most important elements in discriminating otoliths from site 1 and 2 . This procedure identified 6 elements as being important in differentiating between elemental compositions of otoliths; these were ${ }^{51} \mathrm{~V},{ }^{66} \mathrm{Zn},{ }^{109} \mathrm{Ag},{ }^{206} \mathrm{~Pb},{ }^{238} \mathrm{U}$ and ${ }^{62} \mathrm{Ni}$. Using only these 6 elements to rerun the LDA lowers the original cross-validation misclassification rate from $15.83 \%$ to $6.25 \%$. Frequencies of canonical variables are shown as a histogram in Fig. (1).

\section{(iii) Comparison Between Artificial Reef Sites}

Otoliths from L. campechanus collected at the two artificial reef sites were compared to determine if otoliths collected east and west of the Mississippi River could be successfully discriminated. The LDA consisted of $66 \mathrm{~L}$. campechanus otoliths (31 from site 2 in Louisiana and 35 from site 3 in Alabama), the 15 elements analyzed, and two classes (site 2 and site 3 ). All of the multivariate statistics and exact $F$ statistics from this analysis were significant with p-values $<0.0001$. Otoliths collected on Louisiana and Alabama artificial reefs could be successfully discriminated, with a cross-validation misclassification rate of $12.35 \%$. An SDA was performed to determine which elements were the most influential in discriminating otoliths from Louisiana and Alabama artificial reefs (sites 2 and 3). This analysis identified 6 of the 15 elements as being the most important for discrimination. The 6 elements were ${ }^{65} \mathrm{Cu},{ }^{107} \mathrm{Ag},{ }^{208} \mathrm{~Pb}$, ${ }^{59} \mathrm{Co},{ }^{51} \mathrm{~V}$ and ${ }^{238} \mathrm{U}$. The LDA was then rerun using only these 6 elements. Rerunning the analysis in this manner lowers the original cross-validation misclassification rate of $12.35 \%$ to $8.94 \%$. Frequencies of canonical variables are shown as a histogram in Fig. (2).

\section{Canonical Discriminant Analysis (CDA)}

\section{(i) Comparison Among All Three Study Sites}

Although results from LDA and SDA are commonly reported in otolith microchemistry research, a CDA was also used to compare the L. campechanus otolith samples. Although these statistical techniques are similar to one another, the LDA will later allow an otolith of unknown origin to be classified into one of the three habitats mentioned above. The use of CDA allows for better graphical visualization of the discrimination of otolith elemental concentrations from the three study areas.

The first CDA included all study sites to determine what quantitative variables contributed most to the discrimination of L. campechanus otoliths from among the sites. This procedure included all 98 otolith samples, the 15 elements used in the previous analyses, and three classes (site 1, site 2, and site 3) (PROC CANDISC; SAS V 9.0). Based upon results from the CDA, and referring to the pooled with-in class standardized canonical coefficients, a number of different elements were identified as important for discriminating otoliths from all sites (i. e., have high coefficients). The CDA 


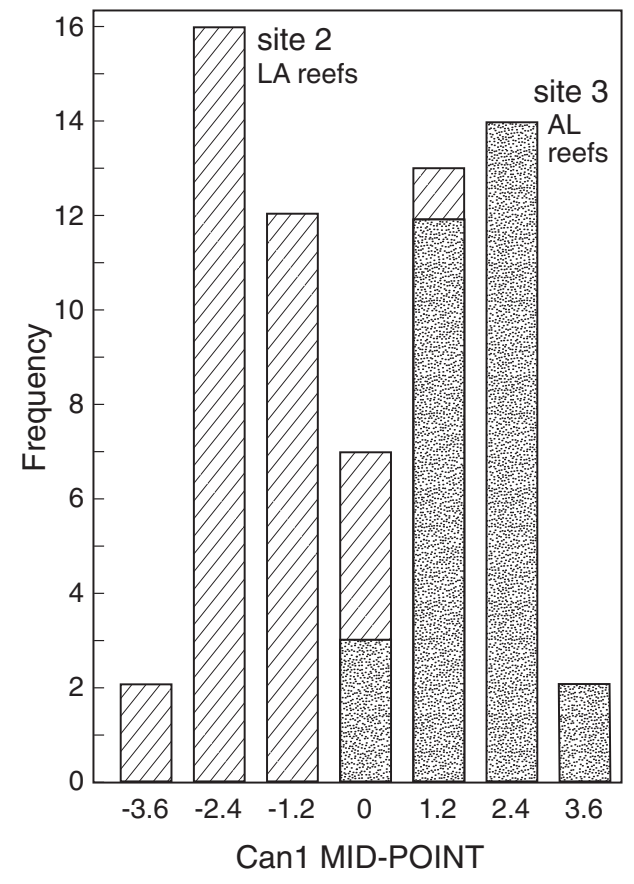

Fig. (2). Vertical bar-graph of canonical variable 1, with observations separated by site, for a comparison of the chemistry of otoliths of Lutjanus campechanus collected from Louisiana artificial reefs (site 2) and Alabama artificial reefs (site 3).

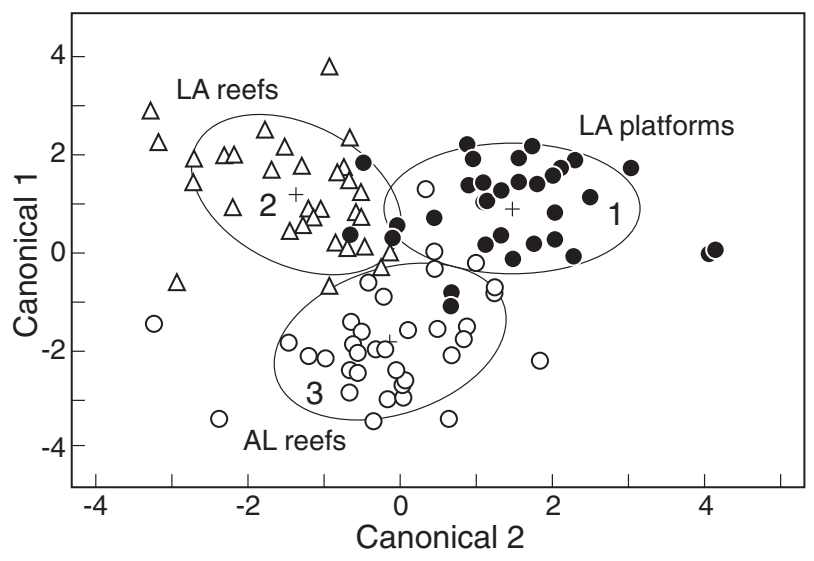

Fig. (3). A scatter-plot of canonical variable 1 versus canonical variable 2, with observations separated by site for a comparison of the chemistry of otoliths of L. campechanus collected form the three study sites Louisiana oil and gas platforms (site1), Louisiana artificial reefs (site 2), and Alabama artificial reefs (site 3).

identified ${ }^{51} \mathrm{~V},{ }^{64} \mathrm{Zn},{ }^{66} \mathrm{Zn},{ }^{207} \mathrm{~Pb}$ and ${ }^{208} \mathrm{~Pb}$ as the most important variables in discriminating between otolith compositions among these three areas. The elements ${ }^{62} \mathrm{Ni},{ }^{107} \mathrm{Ag}$ and ${ }^{114} \mathrm{Cd}$ may also play a role in the discrimination between $L$. campechanus otoliths from the three sites, but these have smaller coefficients than the elements mentioned above. A scatter plot of canonical variable 1 versus canonical variable 2 , with observations separated by site, also shows the discrimination of these three study areas in Fig. (3).

\section{(ii) Comparison Between Louisiana Sites}

A CDA was also performed comparing the elemental composition of otoliths from Louisiana oil and gas platforms (site 1) and Louisiana artificial reefs (site 2). This procedure contained a total of 63 L. campechanus otoliths, all 15 elements, and 2 classes (site 1 and site 2). Based upon results from the CDA, and referring to the pooled with-in class standardized canonical coefficients, 7 elements were identified to be most important (i. e., have high coefficients); these were ${ }^{51} \mathrm{~V},{ }^{109} \mathrm{Ag},{ }^{206} \mathrm{~Pb}$, and $2{ }^{07} \mathrm{~Pb}$. The elements ${ }^{107} \mathrm{Ag},{ }^{208} \mathrm{~Pb}$, and ${ }^{238} \mathrm{U}$ may also play a minor role in the discrimination of site 1 from 2, but their coefficients were smaller.

\section{(iii) Comparison Between Artificial Reef Sites}

Elemental composition of otoliths collected from Louisiana artificial reefs (site 2) and Alabama artificial reefs (site 3 ) were compared using CDA. This comparison contained 66 L. campechanus otoliths, 15 elements, and 2 classes (site 2 and site 3). Based upon results from the CDA, and referring to the pooled with-in class standardized canonical coefficients, 7 of the 15 elements included were identified as being important in discriminating between otoliths from sites 2 and 3 (i. e., have high coefficients); these elements were ${ }^{51} \mathrm{~V},{ }^{62} \mathrm{Ni},{ }^{64} \mathrm{Zn},{ }^{66} \mathrm{Zn},{ }^{207} \mathrm{~Pb},{ }^{208} \mathrm{~Pb}$ and ${ }^{238} \mathrm{U}$. A vertical bar graph of canonical variable 1 , with all 66 otoliths separated by site, showed a clear distinction between the composition of otoliths from Louisiana and Alabama artificial reefs Fig. (2).

\section{Possible Influence of the Mississippi River}

Some elements were important in both the stepwise and canonical discriminant analyses. Of the 15 elements analyzed, 13 re-occurred frequently in the results. The 13 most important elements identified in discrimination of L. campechanus otoliths using the two statistical techniques were ${ }^{51} \mathrm{~V},{ }^{59} \mathrm{Co},{ }^{62} \mathrm{Ni},{ }^{64} \mathrm{Zn},{ }^{66} \mathrm{Zn},{ }^{65} \mathrm{Cu},{ }^{107} \mathrm{Ag},{ }^{109} \mathrm{Ag},{ }^{114} \mathrm{Cd},{ }^{206} \mathrm{~Pb}$, ${ }^{207} \mathrm{~Pb},{ }^{208} \mathrm{~Pb}$ and ${ }^{238} \mathrm{U}$. These elements were important in differentiating between $L$. campechanus otoliths collected from Louisiana oil and gas platforms and artificial reefs, as well as between otoliths from artificial reefs east and west of the Mississippi River. To determine if the concentrations of these important elements were being influenced by the discharge of the Mississippi River, concentrations of the elements in L. campechanus otoliths collected at all three study sites were compared.

It is reasonable to expect that those elements attributable to the Mississippi River discharge should have mean concentrations in otoliths from both Louisiana sites that were significantly higher than in otoliths collected at site 3 in Alabama. The elements that met these criteria were ${ }^{114} \mathrm{Cd},{ }^{65} \mathrm{Cu}$, ${ }^{238} \mathrm{U},{ }^{107} \mathrm{Ag}$ and ${ }^{109} \mathrm{Ag}$, all with means significantly higher in L. campechanus otoliths from coastal Louisiana, west of the Mississippi River (Table 1). Conversely, ${ }^{59} \mathrm{Co}$ and ${ }^{62} \mathrm{Ni}$ had significantly higher means in otoliths from site 3 , east of the Mississippi River, and perhaps reflected discharge from Mobile Bay.

Otolith concentrations of ${ }^{206} \mathrm{~Pb},{ }^{207} \mathrm{~Pb},{ }^{208} \mathrm{~Pb}$ and ${ }^{51} \mathrm{~V}$ did not vary geographically, yet remained significantly higher in otoliths from Louisiana oil and gas platforms than from either artificial reef site. Otolith ${ }^{64} \mathrm{Zn}$ and ${ }^{66} \mathrm{Zn}$ concentrations also showed no significant geographical distribution, but were higher in otoliths collected on Louisiana and Alabama 
Table 1. Summary table of the ICP-MS data (Concentration in ppb) for all Three Study Sites

\begin{tabular}{|c|c|c|c|c|c|c|c|c|}
\hline \multirow[t]{2}{*}{ S. No. } & \multirow[t]{2}{*}{ SAMPLE SET } & & \multicolumn{2}{|c|}{$\begin{array}{l}\text { Gas Platform LA } \\
\text { Samples }(n=32)\end{array}$} & \multicolumn{2}{|c|}{$\begin{array}{c}\text { Artificial Reef LA } \\
\text { Samples }(n=31)\end{array}$} & \multicolumn{2}{|c|}{$\begin{array}{l}\text { Artificial Reef AL } \\
\text { Samples }(n=35)\end{array}$} \\
\hline & & & AVERAGE & STD DEV & AVERAGE & STD DEV & AVERAGE & STD DEV \\
\hline 1. & Vanadium & V 51 & 1.51 & 1.11 & 0.57 & 0.64 & 1.19 & 1.07 \\
\hline 2. & Cobalt & Co 59 & 1.56 & 1.17 & 1.94 & 1.02 & 4.08 & 6.25 \\
\hline 4. & Zinc & Zn 64 & 247 & 84 & 341 & 153 & 317 & 139 \\
\hline 5. & Copper & Cu 65 & 53.4 & 21.8 & 57.2 & 13.0 & 44.9 & 7.6 \\
\hline 6. & Zinc & Zn 66 & 263 & 78 & 369 & 135 & 302 & 132 \\
\hline 10. & Cadmium & Cd 111 & 0.22 & 0.29 & 0.15 & 0.08 & 0.11 & 0.10 \\
\hline 11. & Cadmium & Cd 114 & 0.37 & 0.31 & 0.40 & 0.45 & 0.11 & 0.09 \\
\hline 12. & Lead & Pb 206 & 2.46 & 2.63 & 1.10 & 0.68 & 1.58 & 0.95 \\
\hline 13. & Lead & Pb 207 & 2.34 & 2.51 & 1.10 & 0.61 & 1.46 & 0.88 \\
\hline 14. & Lead & Pb 208 & 2.41 & 2.55 & 1.15 & 0.63 & 1.69 & 1.00 \\
\hline 15. & Uranium & U 238 & 0.07 & 0.19 & 0.08 & 0.20 & 0.01 & 0.07 \\
\hline
\end{tabular}

artificial reefs than in those from Louisiana oil and gas platforms (Table 1).

\section{Trends of Important Elements with Lutjanus cam- pechanus Sex and Total Length}

Any significant relationship between otolith concentration and L. campechanus sex or total length reduces confidence in the concept of an 'oil and gas platform' site-specific marker. Only 2 of the 13 elements $\left({ }^{51} \mathrm{~V}\right.$ and $\left.{ }^{238} \mathrm{U}\right)$ showed a significant relationship with sex in otoliths of L. campechanus. Both had higher mean concentrations in otoliths of male L. campechanus than females at all three study areas. None of the elements show any significant trends when compared to total length.

\section{DISCUSSION}

The use of heavy metal isotopes by Spencer et al. [17] was based on prior knowledge of the differences in petrol lead isotopes known to be abundant in the Kaneohe Bay sediment, and the natural, basaltic, lead isotopes derived from weathering of the base rock of the island of Oahu. In this study of the relationship between the chemistry of the otolith of L. campechanus and the chemistry of oil and gas platforms and artificial reefs, we encountered a similar situation. Oil and gas platforms represent man-made foreign objects in the northern Gulf of Mexico that have a high likelihood of providing heavy metal isotope signals from their mechanical structure. In addition, the drilling muds that are a necessary prerequisite for all oil and gas platforms have a high heavy metal content (particularly $\mathrm{Pb}$ ) that provides the weight that is a necessary part of their function. In a similar fashion, artificial reefs constructed from various types of scrap metals, concrete blocks, etc., also provide a likely source of a heavy metal signal, albeit from a different, or overlapping, suite of elements.

The basic question of this study regarding the chemical fingerprint of the man made objects associated with $L$. campechanus is quite different from the many studies in otolith literature that are based on identifying stocks, or naturally isolated populations of the same species of fish. In this study we have capitalized on an "experiment of industry" that is analogous to an "experiment of nature". Artificial reefs are emplaced and oil and gas wells are drilled and capped without any thought of how the elemental content of the otoliths of fish in the same water mass might be affected. The ongoing presence, however, of the artificial reefs and oil and gas platforms have provided us with as much of an experiment as they would have if they had been put there for that very purpose. Thus, the essentially experimental nature of this study restricts the focus of this paper to the two basic issues of the accuracy of the data, and the validity of the differences in elemental compositions of otoliths observed among the three "treatment groups" of our "experiment of industry" (two groups of artificial reefs and one group of oil and gas platforms). There was a statistically significant sex effect in the distribution of two of the heavy metals, but the small samples involved in this study persuaded us to ignore 
this minor component of the observed variation in otolith elemental composition.

In respect to the accuracy of the measurements of otolith elemental composition, it is well understood that otoliths are unavoidably dirty sampling objects. The dissection process is inherently messy even in the hands of the most skilled. Contamination of the otoliths was controlled as tightly as possible. All samples were treated in exactly the same way as far as it was possible to do so. Errors were no doubt introduced in the handling of otoliths but such errors are likely to be the same for all samples.

Statistical analyses of the differences among "treatment groups" were hampered by not knowing what the underlying distributions of the individual elements were likely to be. Following the bulk of the otolith elemental composition literature, we have made the conventional assumption that the underlying distributions were well behaved and effectively gaussian.

It is clear from our results that the usefulness of otolith microchemistry as a "stock" marker is heavily dependent on what is meant by a "stock". Insofar as artificial reefs and gas platforms lead to a local increase in fish abundance that can be recognised by a "definable attribute of interest to fisheries managers" in the form of certain, shared otolith microchemistry, then they constitute a "stock" in the sense of Begg et al. [11]. At the other end of the scale, the entire population of $L$. campechanus constitutes a "stock" in the sense of international fisheries management agreements between the US and Central American states. The value of otolith microchemistry in stock discrimination is dependent on how fisheries managers are able use otolith chemistry to divide the range of the fish species into definable units.

The results of this study, albeit based on a limited sample, have amply justified our expectations that heavy metal isotope signals from artificial reefs and gas platforms are sufficiently distinct. This conclusion therefore allows recognition of resident $L$. campechanus collected at these sites to within better than $10 \%$ error in the context of the present sample size. Whether these results, like so many other otolith microchemistry results, prove to be unstable, or do not apply to other oil and gas platforms and other artificial, or indeed natural, reefs, only further experiment can decide.

\section{ACKNOWLEDGEMENTS}

We thank the Bureau of Ocean Energy Management, Regulation and Enforcement for funding this project. We are grateful to Yvonne Perry for technical assistance and to Dr Khal Spencer for his advice on the otolith digestion process. We thank Captain Mike Thierry and his crew from Dauphin Island and Captain Steve Tomeny and his crew from Port Fourchon for their expert assistance in collecting Lutjanus campechanus. We thank Brooks Bays and Nancy Hurlbirt from SOEST Illustrations for drafting the figures. We are indebted to the anonymous reviewers for their constructive and helpful commentaries.

\section{REFERENCES}

[1] Gallaway BJ, Martin LR, Howard RL, Boland GS, Dennis GD. Effects on artificial reef and demersal fish and macro-crustacean communities, In: Environmental effects of offshore oil production: the Buccaneer gas and oil field study. B. S. Middleditch (ed.). Mar Sci Vol 14. Plenum Press, New York 1981, pp. 237-299.

[2] Stanley DR, Wilson CA. A fishery-dependent based study of fish species composition and associated catch rates around oil and gas structures off Louisiana. Fish Bull 1990; 88: 719-30.

[3] Goodyear CP. Red Snapper in U. S. waters of the Gulf of Mexico. National Marine Fisheries Service, Southeast Fisheries Science Center, Miami Laboratory, Miami MIA-95/96-05 1995.

[4] Schirripa MJ, Legault CM. Status of L. campechanus in U.S. waters of the Gulf of Mexico: updated through 1998. NMFS, SFD, Miami SFD 99/00-75. 1999.

[5] Behrens-Yamada S, Mulligan TJ, Fairchild SJ. Strontium marking of hatchery reared Coho salmon (Oncorhynchus kisutch), Walbaum). J Fish Biol 1979; 14: 267-75.

[6] Halden NM, Babaluk JA, Krlstofferson AH, et al. Micro-PIXE studies of Sr zoning in Arctic Char otoliths: migratory behavior and stock discrimination. Nuc Instru Meth 1996; BI09/100: 592-7.

[7] Halden NM, Mena SR, Babaluk JA, et al. Oscillatory zinc distribution in Arctic char (Salvelinus alpinus) otoliths: The result of biology or environment? Fish Res 2000; 46: 289-98.

[8] Gauldie R. Taking stock of genetic concepts in fisheries management. Can J Fish Aquat Sci 1991; 48: 722-31.

[9] Marr JC. Contributions to the study of subpopulations of fish. U.S. Dep Inter Fish Wildl Serv Spec Sci Rep Fish No. 208. 1957.

[10] Gulland JA. Ecological aspects of fishery research. Adv Ecol Res 1971; 7: 115-76.

[11] Begg GA, Friedland KD, Pearce JB. Stock identification and its role in stock assessment and fisheries management: an overview. Fish Res 1999; 43: 1-8.

[12] Gauldie RW, Nathan A. Iron content of the otoliths of Tarakihi (Teleostei: Cheilodactylidae). New Zeal J Mar Freshwater Res 1977; 11: 179-91.

[13] Macpherson E, Manriquez M. Varaciones de algunos elementos constituyentes del otolito y sus relaciones con el crecimento de Merluccius capensis. Investig Pesquera 1977; 41: 205-18.

[14] Patterson WFIII, Cowan JH Jr, Graham EY, Lyons WB. Otolith microchemical fingerprints of age-O Lutjanus campechanus for the northern Gulf of Mexico. Gulf Mex Sci 1998; 16 (1): 83-91.

[15] Stumm W. Chemistry of the Solid-Water Interface. WileyInterscience 1992.

[16] Amiard JC, Amiard-Triquet C, Berthet B, Metayer C. Comparative study of the patterns of the bioaccumulation of essential $(\mathrm{Cu}, \mathrm{Zn})$ and non-essential $(\mathrm{Cd}, \mathrm{Pb})$ trace metals in various estuarine and coastal organisms. J Exp Mar Biol Ecol 1987; 106: 73-89.

[17] Spencer K, Shafer DJ, Gauldie RW, Decarlo EH. Stable lead isotope ratios from distinct anthropogenic sources in fish otoliths: a potential nursery ground stock marker. Comp Biochem Phys 2000; Part A 127: 273-84.

[18] Continental Shelf Associates, Inc. Gulf of Mexico comprehensive synthetic based muds monitoring program volume I: technical final report for the SBM Research Group, Shell Global Solutions U. S., Houston, TX 2004.

[19] Neff JM. Biological effects of drilling fluids, drill cuttings, and produced waters, p. 469-538. In: long- term environmental effects of offshore oil and gas development. D. F. Boesch and N. N. Rabalais (eds.). Elsevier Applied Science Publishers, London 1987.

[20] Neff JM, Rabalais NN, Boesch DF. Offshore oil and gas development activities potentially causing long-term environmental effects p. 149-173. In: Long- Tern Environmental Effects of Offshore Oil and Gas Development. D. F. Boesch and N. N. Rabalais (eds.). Elsevier Applied Science Publishers, London 1987.

[21] Mason B, BERRY LG. Elements of mineralogy. W. H. Freeman and Company, San Francisco 1968.

[22] Nowling LK. Platform recruited reef fish, Phase I: Do Platforms provide habitat that increase the survival of juvenile reef fishes? Oceanography \& Coastal Sciences 2005. 11-14. Available from: http://etd.lsu.edu/

[23] Der G, Everitt BS. Principal components analysis and factor analysis: The Olympic decathlon and statements about pain, In: A hand- 
book of statistical analyses using SAS, Second Edition. Chapman and Hall/CRC (eds.). CRC Press LLC, Florida 2002, pp. 237-262.

(C) Nowling et al.; Licensee Bentham Open.

This is an open access article licensed under the terms of the Creative Commons Attribution Non-Commercial License (http://creativecommons.org/licenses/ by-nc/3.0/) which permits unrestricted, non-commercial use, distribution and reproduction in any medium, provided the work is properly cited. 